\title{
Cellular miR-101-1 Reduces Efficiently the Replication of HSV-1 in HeLa Cells
}

\author{
Bahar Sadegh Ehdaei $^{\mathrm{a}} \quad$ Ahmad Pirouzmand $^{\mathrm{a}, \mathrm{b}} \quad$ Mehdi Shabani $^{\mathrm{c}}$ \\ Arezoo Mirzaeic Sharareh Moghim $^{c}$ \\ aDepartment of Microbiology, Kashan University of Medical Sciences, Kashan, Iran; ${ }^{b}$ Autoimmune Diseases Research \\ Center, Faculty of Medicine, Kashan University of Medical Sciences, Kashan, Iran; 'Department of Microbiology, \\ School of Medicine, Isfahan University of Medical Sciences, Isfahan, Iran
}

\section{Keywords}

Herpes simplex virus-1 - MicroRNA · Hsa-miR-101-1 ·

Antiviral therapy

\begin{abstract}
Introduction: Herpes simplex viruses (HSVs) are widely distributed in the human population. HSV type 1 (HSV-1) is responsible for a spectrum of diseases, ranging from gingivostomatitis to keratoconjunctivitis, and encephalitis. The HSVs establish latent infections in nerve cells, and recurrences are common. Their frequent reactivation in elderly and immunosuppressed patients causes serious health complications. Objectives: Due to the growing resistance to its main drug, acyclovir, alternative treatments with different mechanisms of action are required. MicroRNAs regulate host and viral gene expression posttranscriptionally. Previous studies reported that mir-101-2 expression has widely participated in the regulation of HSV-1 replication. In this study, we investigate the effect of hsa-miR-101-1 in the replication of HSV-1. Methods: We found that transfection of miR-101-1 into HeLa cells could reduce effectively HSV-1 replication using plaque assay and real-time PCR methods. Results: We showed that overexpression of miR-10-1 produced less viral
\end{abstract}

karger@karger.com

(c) 2021 S. Karger AG, Basel

www.karger.com/int

Karger progeny and manifested a weaker cytopathic effect, without affecting cell viability. Discussion/Conclusion: This result can give us new insights into the control of HSV-1 infections.

(c) 2021 S. Karger AG, Basel

\section{Introduction}

Herpes simplex virus type 1 (HSV-1), now known as Human alphaherpesvirus 1, is a linear double-stranded DNA virus that infects humans [1]. The HSV infects primarily mucous cells and establishes latent infections in nerve cells, and recurrences are common $[1,2]$. The virus most commonly causes localized mucocutaneous lesions, meningitis, and encephalitis [2]. It can be reactivated by various factors, especially immune deficiency [3]. HSV-1 infection can cause severe diseases in immunocompromised patients and disseminate more easily with increased recurrences [4]. For treatment and suppression of herpetic infection, acyclovir (ACV) is the most available and effective drug, targeting viral DNA replication [5]. However, long-term antiviral

B.S.E. and A.P. contributed equally to this work. 
treatment, mainly in immunocompromised patients, often results in emerging resistance to $\operatorname{ACV}[4,5]$. On the other hand, growing evidence shows that constant treatment by ACV could cause some side effects such as renal failure, which may be more severe in immunocompromised patients $[6,7]$. Therefore, there is a necessity to develop new antiherpes drugs with different mechanisms of action.

MicroRNAs (miRNAs) are small, noncoding RNAs that negatively regulate gene expression by binding to $3^{\prime}$ UTRs (untranslated regions) of target mRNAs, causing target cleavage or translational blockage $[8,9]$. miRNAs are involved not only in normal cell function but also in virus-host interaction and play a key role in the regulation of viral replication $[10,11]$. For example, mir-122, a human liver-specific microRNA, promotes HCV replication [12]. Much evidence has shown that viruses can encode their miRNAs to regulate their own genes and their host genes, in order to evade host immune responses and contribute to viral pathogenesis $[13,14]$. During HSV-1 neuronal latency, the only detected viral RNA is the latency-associated transcript, which are approximately 6 or more miRNAs [15]. In contrast, the lytic cycle pathway involves regulated viral gene expression in which immediate-early genes are required for the efficient expression of early and late genes leading to almost 100 different transcript productions [16]. In addition to the viral miRNAs, viruses can also target host miRNAs and change their expression. miR-132 is a cellular miRNA that is highly upregulated after HSV-1 and human cytomegalovirus (HCMV) infection and facilitates viral replication by suppressing the expression of interferonstimulated genes [17]. Hsa-miR-101, as a well-known miRNA, has two precursors: hsa-miR-101-1 located on chromosome 1p31.3 and miR-101-2 on chromosome $9 \mathrm{p} 24.2$. Both precursors and the mature miR-101 were expressed, mostly in cancers [18]. It has been reported that miR-101-2 is induced in the early stages of HSV-1 infection [19]. Furthermore, HSV-1 ICP4 was shown to bind directly to the miR-101-2 promoter and activate its expression. On the other hand, miR-101-2 downregulates GRSF1 expression, which in turn increases HSV-1 replication [20]. However, the effect of miR-101-1 on the replication of HSV-1 has remained unclear. In the present study, we applied miR-101-1 to study its overexpression effects on HSV-1 replication. Our finding suggests that miR-101-1 could suppress HSV-1 replication in vitro.

\section{Material and Methods}

\section{Cell Culture and Virus}

HeLa cell lines (ATCC CCL-2) were obtained from the National Cell Resource Center of Iran, Pasture Institute (Iran), and grown in Dulbecco's modified Eagle medium (DMEM, high glucose, Sigma-Aldrich, Germany) supplemented with $10 \%$ heat-inactivated fetal bovine serum (FBS, Sigma-Aldrich), 100 Units/mL penicillin, and $100 \mu \mathrm{g} / \mathrm{mL}$ streptomycin at $37^{\circ} \mathrm{C}$ in a humidified incubator containing $5 \% \mathrm{CO}_{2}$. The HSV-1 strain was kindly provided by the Virology Department, Iran University of Medical Sciences (Tehran, Iran). The HSV-1 stock was propagated on HeLa cells, titrated by TCID50, and stored at $-80^{\circ} \mathrm{C}$ [21].

\section{MicroRNA Transfection}

The miRCURYLNA microRNA mimic of miR-101-1 (FAMlabeled at the 5' end) was chemically synthesized by Exiqon (Denmark) according to the mature nucleotide sequences, obtained from www.mirbase.org, as 5'CAGUUAUCACAGUGCUGAUGCU3' (accession number: IMAT0004513). The mock, MiRCURY LNA microRNA "cel-miR-39-3p" (5'TCACCGGGTGTAAATCAGCTTG; product number: 470,928-001), was purchased from Exiqon (Denmark) and used as negative control. HeLa cells were grown at $70-80 \%$ confluence and then transfected with FAM-labeled hsa-miR-101-1 (50 and $100 \mathrm{nM}$ ), mock or without the miRNAs by using Polyfect (Qiagen), according to the manufacturer's protocol. After $24 \mathrm{~h}$, the cells were infected at a multiplicity of infection (MOI) $0.1,1$, and 5 for $1 \mathrm{~h}$ with gentle shaking at 15 -min intervals to allow viral adsorption. The cells were cultured with serum-free DMEM at $37^{\circ} \mathrm{C}$ in a $5 \% \mathrm{CO}_{2}$ incubator [20]. After 2 days, the inhibitory effect of the miRNAs on HSV-1 replication was determined by comparing the cytopathic effect (CPE) of the virus on transfected cells to the nontransfected or mock cells [1].

\section{Cytotoxicity Assay}

The viability of cells after miRNA transfection was determined by MTT assay using 3-(4,5-dimethyl-2-thiazolyl)-2,5-diphenyl-2H-tetrazolium bromide. Cells were plated into a 96-well plate at a density of $1 \times 10^{3} /$ well and transfected with miR-101 mimics and miR-control (50, $100 \mathrm{nM})$. After 24, 48, and $72 \mathrm{~h}$ after transfection, $20 \mu \mathrm{L}$ of MTT dissolved in PBS $(5 \mathrm{mg} / \mathrm{mL})$ was added to each well. The plates were further incubated for $4 \mathrm{~h}$ in the dark. Then, the MTT solution was discarded and $100 \mu \mathrm{L}$ dimethyl sulfoxide was added to each well, and the plates were gently shaken for 15 min at room temperature. The absorbance of each well was measured at $490 \mathrm{~nm}$ using an ELISA reader [22, 23].

\section{Fluorescence Microscopy}

HeLa cells were seeded in 24-well cell culture plates. At 70\% confluency, FAM-labeled miR-101-1 was transfected into the cells at 50 and $100 \mathrm{nM}$ concentrations using Polyfect. At 24, 48, and $72 \mathrm{~h}$ after treatment, the transfection efficacy was visually studied by using a fluorescence microscope (Nikon, Tokyo, Japan).

\section{Plaque Assay}

HeLa cells were grown in 24 -well plates to $80 \%$ confluence and then transfected with miR-101 mimics and the mock as described above. Twenty-four hours later, the transfected cells were infected with HSV- 1 at different MOIs $(0.1,1$, and, 5$)$ and let to adsorb for $1 \mathrm{~h}$ at $37^{\circ} \mathrm{C}$ in a $5 \% \mathrm{CO}_{2}$ incubator with gentle shaking at 15 -min 

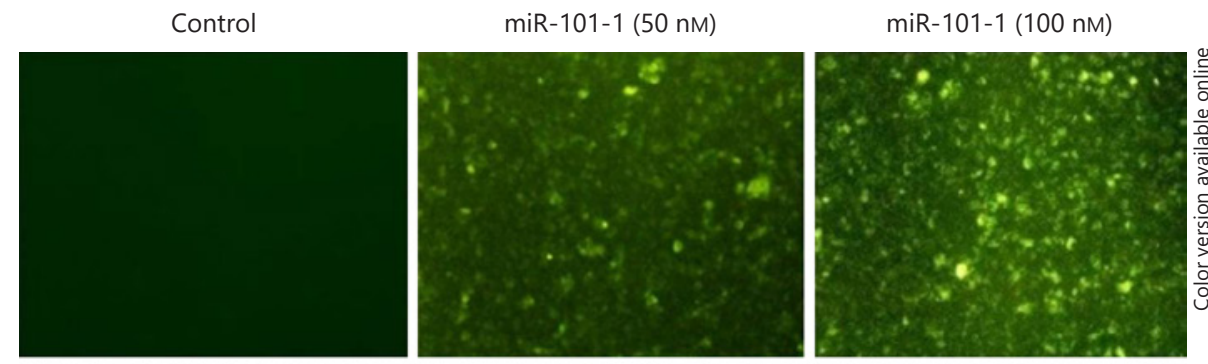

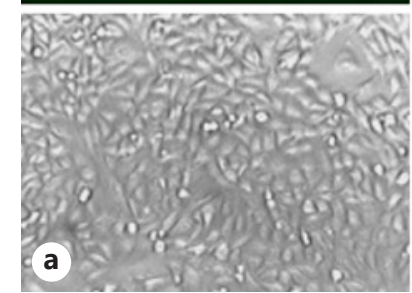

24 h post-transfection

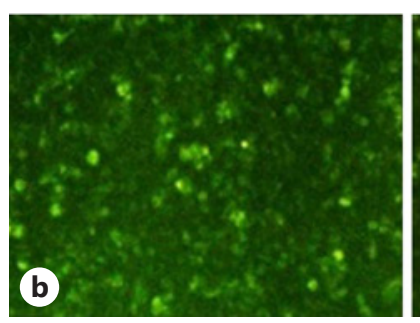

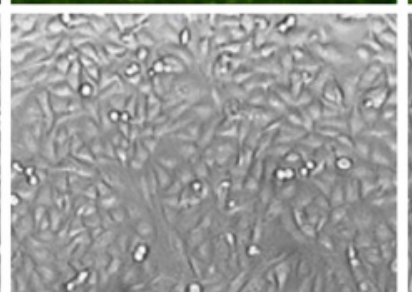

48 h post-transfection

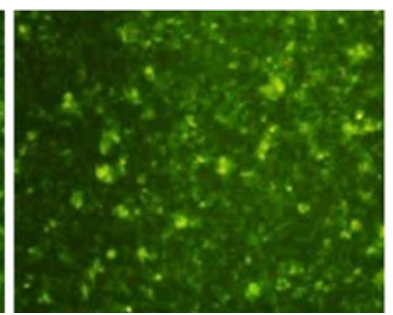

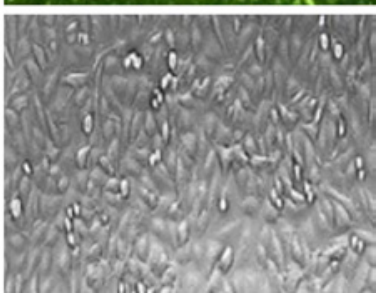

72 h post-transfection

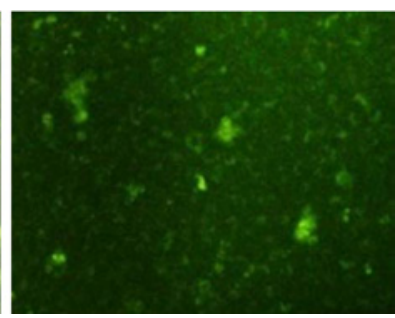

Fig. 1. Transfection efficacy. a FAM-labeled miRNA (50 and $100 \mathrm{nM}$ ) was transfected into HeLa cells. b The transfection efficacy of the miRNA was visually detected by fluorescent microscopy 24,48 , and $72 \mathrm{~h}$ after transfection. Magnification, $\times 400$. miRNA, microRNA.

intervals. Then, supernatants were aspirated, and the cells were washed two times with PBS and overlaid with $1 \mathrm{~mL}$ of a 1:1 mixture of Noble agar (Difco, NJ, USA) and $2 \times$ DMEM/high glucose. Forty-eight hours after infection, agarose was removed carefully and the plates were fixed with $10 \%$ paraformaldehyde for $15 \mathrm{~min}$ and stained with $1 \%$ crystal violet for $20 \mathrm{~min}$ [24]. Plaques were counted and photographed, and the plaque reduction ratio was calculated [25].

\section{Quantitative Real-Time PCR}

DNA was extracted from the HSV-1-infected cells. The cells were washed three times with PBS, then digested in $500 \mu \mathrm{L}$ lysis buffer (10 mM Tris-HCl pH 7.4, $0.1 \mathrm{M}$ EDTA, 0.5\% SDS, and $20 \mathrm{~g} /$ $\mathrm{mL}$ RNase A), and incubated for $1 \mathrm{~h}$ at $37^{\circ} \mathrm{C}$. The DNA of the samples was extracted with phenol-chloroform followed by precipitation with $100 \%$ alcohol in the presence of $0.3 \mathrm{M}$ sodium acetate. The DNA pellets were washed with $70 \%$ alcohol, dried, and suspended in $100 \mu \mathrm{L}$ of sterile TE buffer and stored at $-20^{\circ} \mathrm{C}$ [17]. SYBR Green-based quantitative PCR was performed to detect the relative level of UL47. The set of primers used for UL47 were as follows: forward, 5'GACGTACGCGATGAGATCAA3' and reverse, 5'GTTACCGGATTACGGGGACT3' [26]. Human betaglobin was used as an internal control gene [27]. All PCRs were performed in a $20-\mu \mathrm{L}$ volume containing Real Q plus master mix green (Ampliqon). The reaction conditions were $95^{\circ} \mathrm{C}$ for $10 \mathrm{~min}$, 40 cycles of $95^{\circ} \mathrm{C}$ for $10 \mathrm{~s}, 65^{\circ} \mathrm{C}$ for $20 \mathrm{~s}$, and $72^{\circ} \mathrm{C}$ for $30 \mathrm{~s}$, and $72^{\circ} \mathrm{C}$ for 5 min by using the ABI Step-one (Applied Biosystems, Foster City, CA, USA). Each run was completed with a melting curve analysis to confirm the specificity of the amplification. The real-

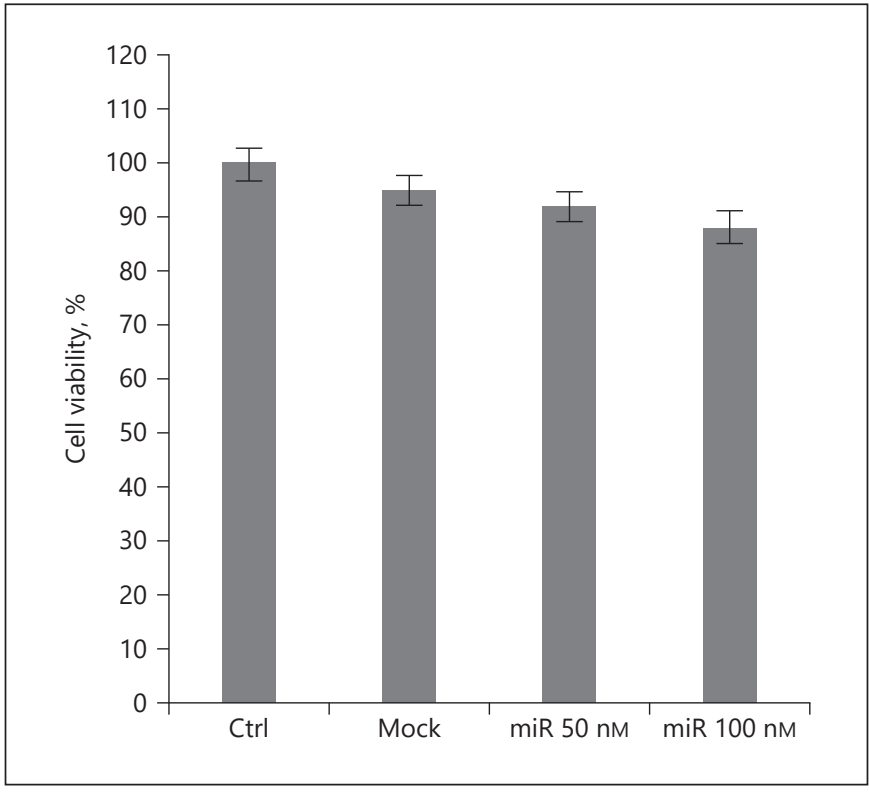

Fig. 2. Cell viability with miR-101-1 mimics and mock at different concentrations was assessed by MTT assay. Each sample was analyzed in triplicate $(p>0.05)$.
90

Intervirology 2021;64:88-95

DOI: $10.1159 / 000512956$
Sadegh Ehdaei/Pirouzmand/Shabani/ Mirzaei/Moghim 

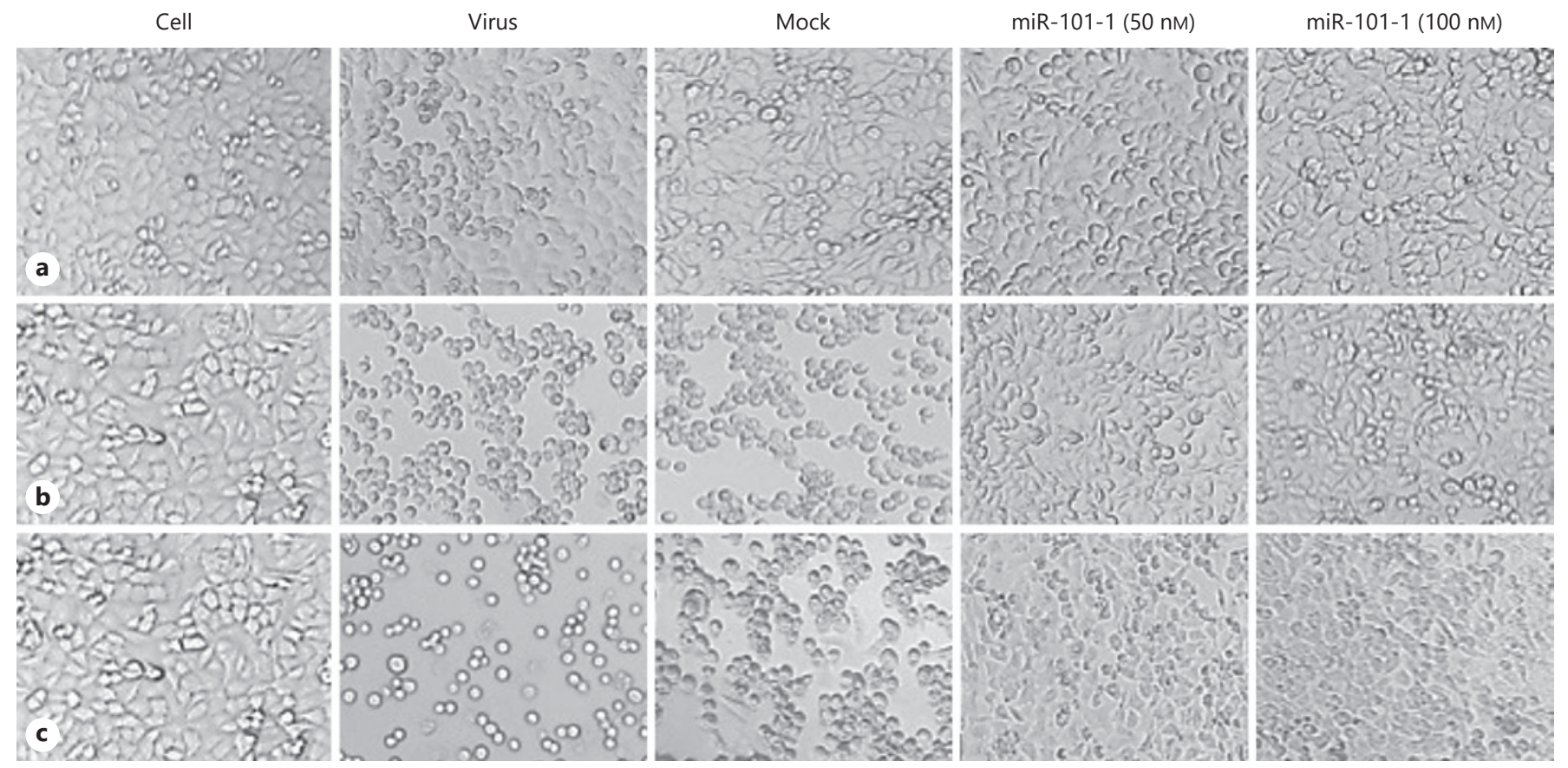

Fig. 3. MiR-101-1 effects on HSV-1 production in HeLa cells. HeLa cells were transfected with miR-101-1 mimics (50 and $100 \mathrm{nM}$ ) and mock (control miR $100 \mathrm{nM}$ ), followed by HSV-1 infection with MOI 0.1 (a), 1 (b), and 5 (c), $24 \mathrm{~h}$ after transfection. The cellular changes (CPE) were imaged at $24 \mathrm{~h}$ after infection. The CPE clear-

time PCR results were analyzed by the $\Delta \Delta$ Ct method. The relative quantification of each experiment was calculated using the $2 \Delta \Delta \mathrm{CT}$ method [21].

\section{Statistical Analysis}

Statistical significance $(p<0.05)$ was determined using Student's $t$ test. Data are presented as mean \pm SD. All generated data represent at least three separate experiments in triplicate.

\section{Results}

Transfection Conditions of miR-101-1 in HeLa Cells

Transfection conditions were optimized to obtain the highest level of transfection efficiency, without inducing toxicity. The efficiency and the sustainability of FAM-labeled hsa-miR-101-1 in the cells were determined by fluorescent microscopy. We used two concentrations of miR-101 (50 and $100 \mathrm{nM}$ ). As shown in Figure 1a, the transfection efficiency increased in a $100 \mathrm{nM}$ concentration of miR-101-1. The transfection efficiency reached up to $85 \%$ at $24 \mathrm{~h}$ after transfection. After $48 \mathrm{~h}$, the durability of transfection remained constant but decreased on the third day (Fig. 1b).

Mir-101-1 Reduces the Replication of HSV-1 in vitro ly increased in cells untreated with miRNA. The CPE and giant multinucleated cells dramatically decreased in cells treated with miR-101-1 mimics. HSV, herpes simplex virus; HSV-1, HSV type 1; MOI, multiplicity of infection; CPE, cytopathic effect.

We used the MTT assay to evaluate the cytotoxicity levels of miR-101-1 (Fig. 2). The viability of HeLa cells in different concentrations of miR-101-1 remained unchanged $(p>0.05)$.

\section{Effect of miR-101-1 on HSV-1 Replication in Infected} HeLa Cells

HeLa cells were transfected with 50 and $100 \mathrm{nM}$ concentrations of miR-101-1 mimic or mock miRNA. At $24 \mathrm{~h}$ after transfection, the cells were observed under a fluorescence microscope for transfection efficiency. Then, the transfected cells were infected with HSV-1 at different MOIs (0.1, 1, and 5). Cellular morphological changes were observed $24 \mathrm{~h}$ after infection and photographed. HSV-1 can establish a severe CPE. Infected cells usually show clusters. As shown in Figure 3, cells transfected by the miR-101-1 mimic showed a significant decrease in the CPE in a dose-dependent manner, with full inhibition at $100 \mathrm{nM}$ concentration of miR-101-1. The CPE increased clearly in HSV-1-infected cells alone or cells transfected with the mock miRNA control. 


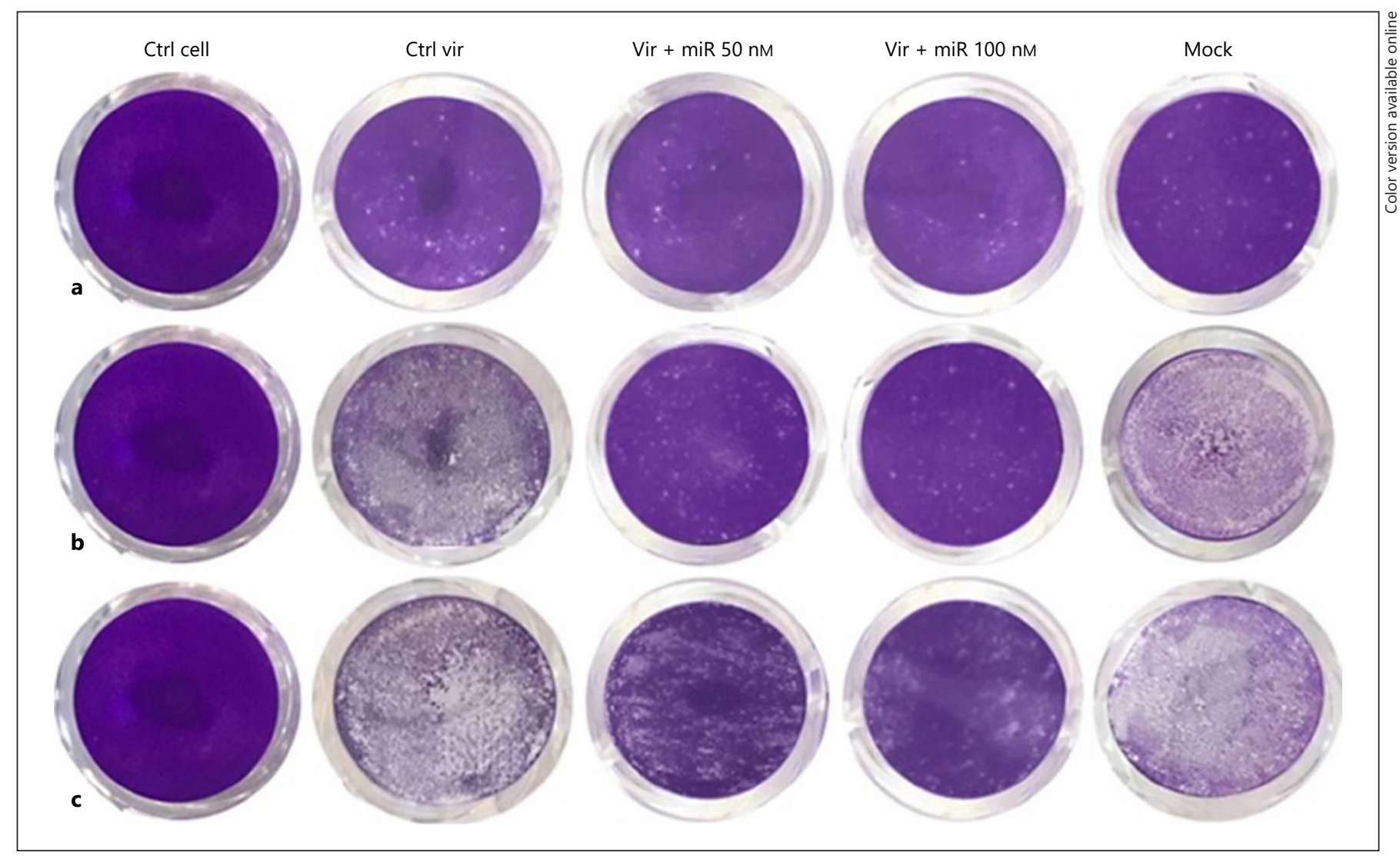

Fig. 4. Effect of miR-101-1 and mock on plaque formation. HeLa cells were transfected with miRNAs at an indicated concentration and infected with HSV-1 at MOI 0.1 (a), 1 (b), and 5 (c). Plaques were counted $72 \mathrm{~h}$ later compared with the virus control group. MOI, multiplicity of infection.

\section{HSV-1 Titer in the Transfected HeLa Cells}

The antiviral activity of miR-101-1 was analyzed using standard plaque assay as a gold standard phenotypic method. Compared to nontransfected HeLa cells, those transfected with miR-101-1 mimic produced significantly fewer plaques (Fig. 4, $p<0.05$ ). The reduction of virus progeny validated the inhibitory effect of miR-101-1 in the HeLa cells (Fig. 5).

\section{HSV-1 DNA Level in miRNA-Treated Cells}

Viral yield results confirmed the antiviral activity of miR-101-1 in the HeLa cells. We used real-time PCR with primers targeting the UL 47 gene for viral quantification. As shown in Figure 6, miR-101-1 expression reduced virus yields significantly $(p<0.05)$.

\section{Discussion}

MicroRNAs play important roles in physiological and pathological processes, including tumor-suppressing functions and host-virus interactions [28]. Host miRNAs directly target viral RNAs to activate or inhibit viral replication [29]. Some viruses, including the herpesviruses, may modulate the profile of host cell miRNAs to facilitate their replications [30]. HSV-1 lytic infection and reactivation from latency depend on viral ICP0, which is controlled by miR-138 in neurons [31]. Therefore, host- or virus-encoded miRNAs and their target genes together constitute a regulatory system between the host and the virus. In this study, we examined the effect of host-encoded miR-101-1 on HSV-1 infection and realized that miR101-1 has an antiviral effect. Currently, miRNA manipulation is used in the development of antiviral drugs [32]. However, only a few studies have studied the therapeutic capacity of microRNAs to treat HSV-1 infections. Wang 
et al. [20] reported that miR-101-2 attenuates HSV-1 viral replication [18]. In the present study, we research the effect of another type of miR-101, miR-101-1 (-5p), which has different cellular targets. We found that exogenous

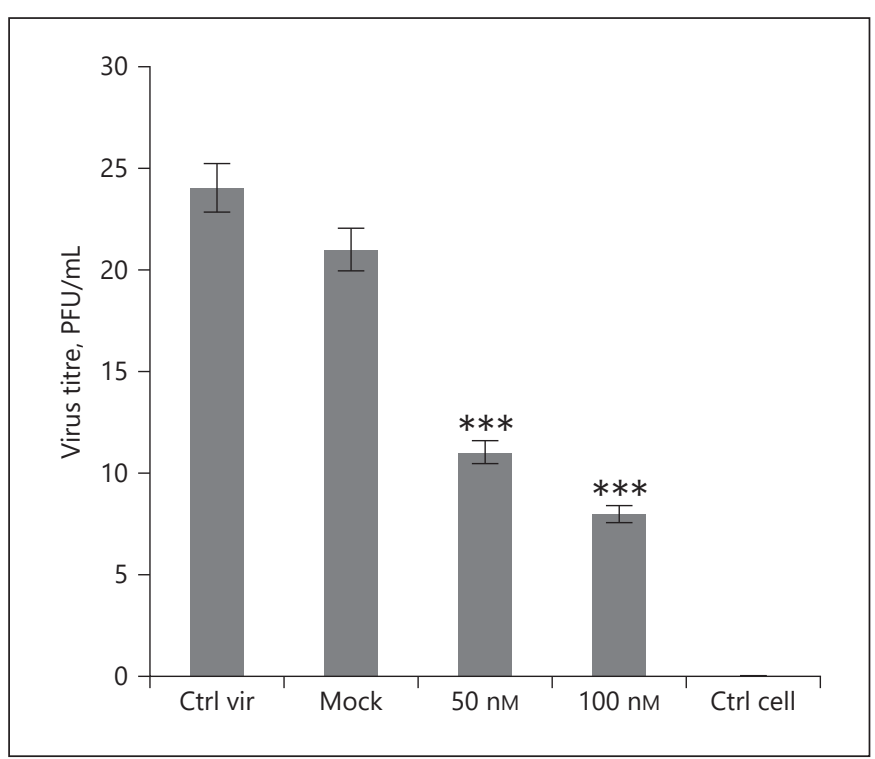

Fig. 5. Viral yield results validate the antiviral activity of miR-1011 in HeLa cells as it reduced viral production about 54\% at MOI 0.1 for miR-101-1 $50 \mathrm{nM}$ and $66 \%$ for miR-101-1,100 nM, compared to the mock (miR control) or virus control. Significantly lower levels of plaque formation could be seen in cells transfected by miR-101-1 ( $p<0.001$ miR-101-1 vs. mock or HSV-1 alone). HSV, herpes simplex virus; HSV-1, HSV type 1; MOI, multiplicity of infection. mimic miR-101-1 expression exhibits significant antiHSV-1 properties and decreases CPE formation up to $66 \%$ compared to the controls. We examined the effect of miR-101-1 mimic on HSV-1 replication, at both high and low MOIs. The course of infection is very different between a lower and a higher MOI; with a high MOI, the effect of HSV-1-infected cells can be seen, but it is difficult to see the effects derived from reinfections (viruses produced in cells infecting others). Since the expression of miR-101-1 inhibits virus production in the early and late stages of infection, it is likely that one of the viral transactivators of the promoter required for the expression of the early and late HSV-1 genes could be involved in this process and should be considered in future research. There are 2 different loci of the miR-101 gene in the human genome: Hsa-miR-101-1 on chromosome 1 and mir-101-2 on chromosome 9. Recently, Wang et al. [20] showed that the HSV-1 immediate early gene, ICP4, binds to the promoter of cellular miR-101-2 (-3p) and activates its expression. This cellular miRNA regulates the RNA-binding Grich sequence factor 1 (GRSF1). GRSF-1 is a new cellular target of mir-101-2 and is necessary for HSV-1 replication. MiR-101-1 has different cellular targets (https:// blast.ncbi.nlm.nih.gov/Blast.cgi). Whether the expression of miR-101-1 directly targets viral genes or host cellular genes that regulate HSV-1 replication needs to be further evaluated. We have also reported that a higher concentration of miR-101-1was more effective, with almost full inhibition of virus replication being at $100 \mathrm{nM}$. Jin et al. [33] also found that the concentration and accu-
Fig. 6. Effect of miR-101-1 on viral genome load. HeLa cells were transfected with 50 and $100 \mathrm{nM}$ of miR-101-1 and mock and infected with HSV-1 at MOI 0.1, 1, and 5. Eighteen hours after infection, the DNA was extracted and the relative level of viral DNA was quantified. Data are analyzed as the mean of three individual experiments. ***Significant level $<0.001$ of the MannWhitney test compared to control virus. $\uparrow \uparrow$ Significant level $<0.01$ of the MannWhitney test compared to control virus. $\dagger \dagger \dagger$ Significant level $<0.001$ of the MannWhitney test compared to control virus. HSV, herpes simplex virus; HSV-1, HSV type 1; MOI, multiplicity of infection.

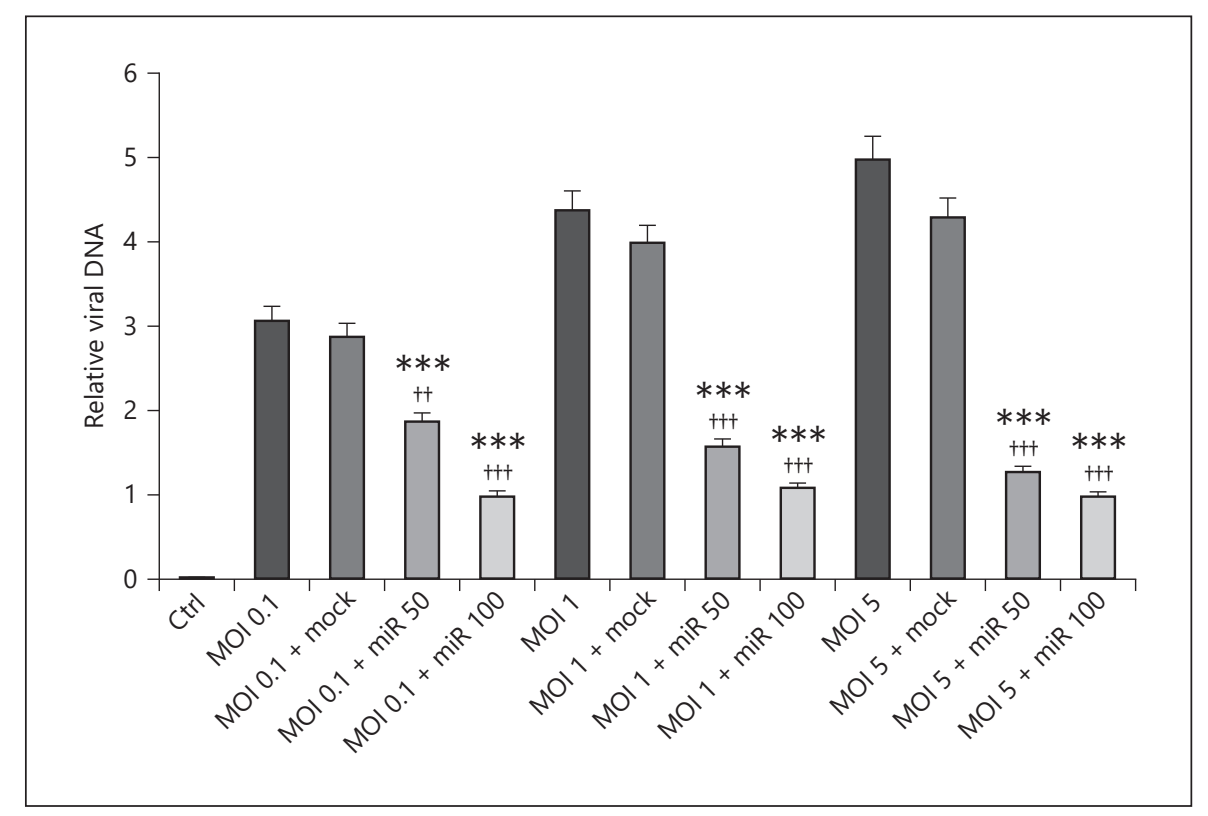

Mir-101-1 Reduces the Replication of HSV-1 in vitro
Intervirology 2021;64:88-95 DOI: $10.1159 / 000512956$ 
mulation of miRNA mimic in HeLa cells is time and dose dependent with the optimal effect being $72 \mathrm{~h}$ after transfection. In our study, miR-101 stability decreased during the previously stated lengths of time, and the best results related to 24-48 h after transfection based on the results of fluorescent microscopy. By quantification of the viral genome copy number in the cells, we found that overexpression of miR-101-1 greatly reduces total viral loads in transfected cells.

\section{Conclusion}

Our results showed that cellular hsa-miR-101-1 overexpression attenuates efficiently HSV-1 replication. Overall, this study provides new insights into the antiviral role of miR-101 in HSV-1 replication and confers new targets to inhibit HSV-1 replication by alternative methods.

\section{Acknowledgement}

We are grateful to Dr. H.R. Monavari (Iran University of Medical Sciences, Iran) for providing HSV-1 strains.

\section{Statement of Ethics}

This work involves no living subjects; therefore, ethical approval is not required.

\section{Conflict of Interest Statement}

The authors declare no conflict of interest.

\section{Funding Sources}

This work was supported by grants from Kashan University of Medical Sciences (Grant No. 96161).

\section{Author Contributions}

B.S.E. performed laboratory testing and experiments and coordination in data analysis and wrote the manuscript. A.P. provided invaluable comments on the text of the manuscript and coordinated data analysis. M.S. helped in performing laboratory testing and data analysis. A.M. participated in performing real-time PCR and data analysis. S.M. conceived the study design, helped in laboratory testing, supervised the project, and provided invaluable comments on the text of the manuscript.

\section{References}

1 Duan F, Liao J, Huang Q, Nie Y, Wu K. HSV1 miR-H6 inhibits HSV-1 replication and IL-6 expression in human corneal epithelial cells in vitro. Clin Dev Immunol. 2012;2012: 192791-204.

2 Ru J, Sun H, Fan H, Wang C, Li Y, Liu M, et al. MiR-23a facilitates the replication of HSV1 through the suppression of interferon regulatory factor 1. PLoS One. 2014;9 (12): e114021.

3 Xu F, Sternberg MR, Kottiri BJ, McQuillan GM, Lee FK, Nahmias AJ, et al. Trends in herpes simplex virus type 1 and type 2 seroprevalence in the United States. JAMA. 2006; 296(8):964-73.

4 Herget GW, Riede UN, Schmitt-Gräff A, Lübbert M, Neumann-Haefelin D, Köhler G. Generalized herpes simplex virus infection in an immunocompromised patient: report of a case and review of the literature. Pathol Res Pract. 2005;201(2):123-9.

5 Wilson SS, Fakioglu E, Herold BC. Novel approaches in fighting herpes simplex virus infections. Expert Rev Anti Infect Ther. 2009; 7(5):559-68.

6 Duan R, de Vries RD, Osterhaus AD, Remeijer L, Verjans GM. Acyclovir-resistant corneal HSV-1 isolates from patients with herpetic keratitis. J Infect Dis. 2008;198(5):659-63.
7 Kakiuchi S, Tsuji M, Nishimura H, Yoshikawa T, Wang L, Takayama-Ito M, et al. Association of the emergence of acyclovir-resistant herpes simplex virus type 1 with prognosis in hematopoietic stem cell transplantation patients. J Infect Dis. 2017;215(6):865-73.

8 Farooq AV, Shukla D. Herpes simplex epithelial and stromal keratitis: an epidemiologic update. Surv Ophthalmol. 2012;57(5):44862.

9 Lam NN, Weir MA, Yao Z, Blake PG, Beyea MM, Gomes T, et al. Risk of acute kidney injury from oral acyclovir: a population-based study. Am J Kidney Dis. 2013;61(5):723-9.

10 Shapolova EG, Lomovskii OI, Kazachinskaya EI, Loktev VB, Teplyakova TV. Antiviral activity of SIO2-polyphenol composites prepared mechanochemically from plant raw materials. Pharm Chem J. 2016;50(9):595-9.

11 Yan Y, Luo YC, Wan HY, Wang J, Zhang PP, Liu M, et al. MicroRNA-10a is involved in the metastatic process by regulating Eph tyrosine kinase receptor A4-Mediated epithelial-mesenchymal transition and adhesion in hepatoma cells. Hepatology. 2013;57(2):667-77.
12 Bartel DP. MicroRNAs: target recognition and regulatory functions. Cell. 2009;136(2): $215-33$

13 Jia X, Bi Y, Li J, Xie Q, Yang H, Liu W. Cellular microRNA miR-26a suppresses replication of porcine reproductive and respiratory syndrome virus by activating innate antiviral immunity. Sci Rep. 2015;5:10651.

14 Lanford RE, Hildebrandt-Eriksen ES, Petri A, Persson R, Lindow M, Munk ME, et al. Therapeutic silencing of microRNA-122 in primates with chronic hepatitis $C$ virus infection. Science. 2010;327(5962):198-201.

15 Perng GC, Dunkel EC, Geary PA, Slanina SM, Ghiasi H, Kaiwar R, et al. The latency-associated transcript gene of herpes simplex virus type 1 (HSV-1) is required for efficient in vivo spontaneous reactivation of HSV-1 from latency. J Virol. 1994;68(12):8045-55.

16 Jurak I, Kramer MF, Mellor JC, Van Lint AL, Roth FP, Knipe DM, et al. Numerous conserved and divergent microRNAs expressed by herpes simplex viruses 1 and 2 . J Virol. 2010;84(9):4659-72.

17 Lagos D, Pollara G, Henderson S, Gratrix F, Fabani M, Milne RS, et al. miR-132 regulates antiviral innate immunity through suppression of the p300 transcriptional co-activator. Nat Cell Biol. 2010;12(5):513.
Sadegh Ehdaei/Pirouzmand/Shabani/ Mirzaei/Moghim 
18 Hao Y, Gu X, Zhao Y, Greene S, Sha W, Smoot DT, et al. Enforced expression of miR-101 inhibits prostate cancer cell growth by modulating the COX-2 pathway in vivo. Cancer Prev Res. 20112010;4(7):1073..;

19 Zheng SQ, Li YX, Zhang Y, Li X, Tang H. MiR-101 regulates HSV-1 replication by targeting ATP5B. Antiviral Res. 2011;89(3):21926.

20 Wang X, Diao C, Yang X, Yang Z, Liu M, Li $\mathrm{X}$, et al. ICP4-induced miR-101 attenuates HSV-1 replication. Sci Rep. 2016;6:23205.

21 Shabani M, Esfahani B, Ehdaei B, Moghim S, Mirzaei A, Sharifi M, et al. Inhibition of herpes simplex virus type 1 replication by novel hsa-miR-7704 in vitro. Res Pharma Sci. 2019; 14(2):167-74.

22 Roehm PC, Shekarabi M, Wollebo HS, Bellizzi A, He L, Salkind J, et al. Inhibition of HSV-1 replication by gene editing strategy. Sci rep. 2016;6:23146.

23 van Meerloo J, Kaspers GJL, Cloos J. Cell sensitivity assays: the MTT assay. Cancer cell culture. New York: Springer; 2011. vol. 731; p. 237-45.
24 Russell TA, Stefanovic T, Tscharke DC. Engineering herpes simplex viruses by infectiontransfection methods including recombination site targeting by CRISPR/Cas 9 nucleases. J Virol Methods. 2015;213:18-25.

25 Duan F, Ni S, Nie Y, Huang Q, Wu K. Small interfering RNA targeting for infected-cell polypeptide 4 inhibits herpes simplex virus type 1 replication in retinal pigment epithelial cells. Clin Exp Ophthalmol. 2012;40(2):195204.

26 Jin F, Li S, Zheng K, Zhuo C, Ma K, Chen M, et al. Silencing herpes simplex virus type 1 capsid protein encoding genes by siRNA: a promising antiviral therapeutic approach. PloS one. 2014;9(5):e96623.

27 Harbecke R, Oxman MN, Arnold BA, Ip C, Johnson GR, Levin MJ, et al. A real-time PCR assay to identify and discriminate among wild-type and vaccine strains of varicella-zoster virus and herpes simplex virus in clinical specimens, and comparison with the clinical diagnoses. J Med Virol. 2009;81(7):1310-22.

28 Skalsky RL, Cullen BR. Viruses, microRNAs, and host interactions. Annu Rev Microbiol. 2010;64(2):123-41.
29 Zhang Y, Dai J, Tang J, Zhou L, Zhou M. MicroRNA-649 promotes HSV-1 replication by directly targeting MALT1. J Med Virol. 2017; 89(6): 1069-79.

30 Zheng K, Liu Q, Wang S, Ren Z, Kitazato K, Yang D, et al. HSV-1-encoded microRNA miR-H1 targets Ubr1 to promote accumulation of neurodegeneration-associated protein. Virus Genes. 2018;54(3):343-50.

31 Pan D, Flores O, Umbach JL, Pesola JM, Bentley $\mathrm{P}$, Rosato PC, et al. A neuron-specific host microRNA targets herpes simplex virus-1 ICP0 expression and promotes latency. Cell Host Microbe. 2014;15(4):446-56.

32 Santhakumar D, Forster T, Laqtom NN, Fragkoudis R, Dickinson P, Abreu-Goodger $\mathrm{C}$, et al. Combined agonist-antagonist genome-wide functional screening identifies broadly active antiviral microRNAs. Proc Natl Acad Sci U S A. 2010;107(31):13830-5.

33 Jin HY, Gonzalez-Martin A, Miletic AV, Lai M, Knight S, Sabouri-Ghomi M, et al. Transfection of microRNA mimics should be used with caution. Front Genet. 2015;6:340. 